Published in final edited form as:

J Environ Econ Manage. 2017 September ; 85: 81-94. doi:10.1016/j.jeem.2017.04.001.

\title{
Happiness in the Air: How Does a Dirty Sky Affect Mental Health and Subjective Well-being? ${ }^{*}$
}

\author{
Xin Zhang, \\ National School of Development, Peking University, xin.zhang614@pku.edu.cn \\ Xiaobo Zhang, and \\ National School of Development, Peking University, International Food Policy Research Institute, \\ x.zhang@nsd.edu.cn \\ Xi Chen \\ Department of Health Policy and Management, Department of Economics, Yale University, New \\ Haven, CT 06520, xi.chen@yale.edu
}

\begin{abstract}
Previous studies evaluating the welfare cost of air pollution have not paid much attention to its potential effect on mental health and subjective well-being (SWB). This paper attempts to fill the gap by investigating the impact of air pollution on several key dimensions, including mental health status, depressive symptoms, moment-to-moment happiness, and evaluative happiness. We match a nationwide longitudinal survey in China with local air quality and rich weather conditions according to the exact time and place of survey. By making use of variations in exposure to air pollution for the same individuals over time, we show that air pollution reduces hedonic happiness and increases the rate of depressive symptoms, while life satisfaction has little to do with the immediate air quality. Our results shed light on air pollution as an important contributor to the Easterlin paradox that economic growth may not bring more happiness.
\end{abstract}

\section{Keywords}

mental health; depression; hedonic happiness; life satisfaction; air pollution; Easterlin paradox

\footnotetext{
*Financial supports from the James Tobin 2014 Summer Research Fund at Yale Economics Department, a NIH/NIA grant (1 R03 AG048920) (2014-2016), the U.S. PEPPER Center Career Development Award (P30AG021342) (2016-2018), and the Yale Macmillan Center Faculty Research Award on air pollution study (2013-2015) are acknowledged. We appreciate the Institute of Social Science Survey at Peking University for providing us with the China Family Panel Studies (CFPS) data and the Qingyue Open Environmental Data Center for collecting the air quality data. The views expressed herein and any remaining errors are the author's and do not represent any official agency.

Correspondence to: Xi Chen.

Publisher's Disclaimer: This is a PDF file of an unedited manuscript that has been accepted for publication. As a service to our customers we are providing this early version of the manuscript. The manuscript will undergo copyediting, typesetting, and review of the resulting proof before it is published in its final citable form. Please note that during the production process errors may be discovered which could affect the content, and all legal disclaimers that apply to the journal pertain.
} 


\section{Introduction}

It has been well documented that exposure to air pollution increases more tangible health risks, such as cardiovascular diseases (Gallagher et al. 2010), respiratory diseases (Moretti and Neidell 2011; Beatty and Shimshack 2014), hospitalizations (Neidell 2009; LlerasMuney 2010), and mortality (Jayachandran 2009; Chen et al. 2013; Greenstone and Hanna 2014; Tanaka 2015). However, much less is known about how air pollution impairs less tangible outcomes like SWB and mental health, which complement the direct monetary measures of welfare (Graham 2005). The burgeoning literature on economics of happiness has promoted more and more countries to incorporate happiness as an important component in policy making and measuring economic and social well-being (Levinson 2013).

The few existing studies on the link between air pollution and happiness primarily rely on aggregate pollution and happiness data (Menz 2011) or individual-level repeated crosssectional data (Levinson 2012). Studies based on aggregated data, however, are subject to the ecological fallacy. That is, the findings may differ or even contradict each other depending on the level of aggregation (Deaton and Lubotsky 2003). Studies at the individual level on the basis of cross-sectional data, on the other hand, are prone to estimation biases because of the difficulty in taking into account all time-invariant factors.

Moreover, few studies use well-matched air pollution and survey data. For example, monitoring stations often only record ambient concentrations every few days (Levinson 2012), and air pollution data tend to be aggregated over a rather long period, such as one year (Ferreira et al. 2013). Consequently, the matched air pollution may differ from the actual exposure and the resultant measurement errors may cause biased estimates.

Furthermore, the literature has not distinguished the impact of air pollution on hedonic and evaluative measures of happiness (Levinson 2012). As noted in Kahneman and Deaton (2010) and Deaton and Stone (2013), the two measures could yield drastically different results because they are often influenced by different factors. Hedonic happiness refers to moment-to-moment experienced utility and directly links to immediate emotions and affection, while evaluative happiness, such as life satisfaction, reflects an overall assessment of the entire life and therefore is less likely subject to short-term changes in external environment. To address these concerns, we employ a novel national longitudinal survey in China with rich measures of hedonic and evaluative happiness as well as mental health in combination with contemporaneous air quality and weather conditions at the time and place of each interview. The well-matched air quality measure more precisely reflects environmental amenities facing interviewees than the heretofore often used measure of average air quality over a certain period. Changes in air quality across days in a given location have little to do with the characteristics of individual respondents. Therefore, the longitudinal feature of the survey enables us to account for individual characteristics. Our identifying assumption is that air pollution exposures are as good as random after accounting for these factors.

We find that higher air pollution index (API) significantly reduces hedonic happiness and raises the rate of depressive symptoms. The impact on life satisfaction, however, is largely 
muted, possibly due to hedonic adaptation over time. Specifically, a one standard deviation (SD) improvement in a single-day air quality identified is associated with 0.03-0.04 SDs improvement in mental health. This identified impact is sizable when compared with other studies that also use standard clinic measures of mental health. ${ }^{1}$ Meanwhile, a decrease of one SD in API boosts hedonic happiness (scaled from 0 to 4 ) by 0.034 , which is a little smaller than the impact of relative income status (0.039), one of the most important determinants of happiness in the literature. The increase in API accounts for 22.5 percent of the actual decline in happiness from 2007 to 2014

Our findings on hedonic happiness also contributes to the debate about the Easterlin paradox, that is, the observation that over time happiness does not display a strong correlation with income growth, while rich people are generally happier than the poor at any given time. While there is a large body of literature explaining the Easterlin paradox, few studies have explained the puzzle from the viewpoint that worsening air quality accompanying economic growth in less-developed countries might reduce happiness, which is the focus of our paper. ${ }^{2}$

We evaluate the willingness to pay (WTP) for better air quality, a time-varying local public good, in monetary value according to our estimates of air pollution on hedonic happiness. ${ }^{3}$ The loss of the amenity value of air quality is sizable. Specifically, people on average are willing to pay $¥ 258$ ( $\$ 42$, or $2.0 \%$ of annual household per capita income) for a one-unit reduction in API per year per person. In other words, a one SD improvement of air quality raises an average person’s happiness by an amount worth $¥ 26$ (\$4) per day.

Our study also relates to the broader literature on the effect of air pollution on a wide variety of topics. For example, recent economics studies have found sizable economic losses in terms of decline in worker/student productivity due to exposure to transitory air pollution. 4 In addition to physiological pathways, psychological pathways may also play an important role. ${ }^{5}$ Our paper contributes to this literature by directly testing the link between air pollution and few key psychological outcome variables, including mental health and happiness, which in turn impede productivity.

While our identified effects are mainly contemporaneous, given the large number of polluted days in each year in many developing countries, the transitory effects may persist and eventually become permanent. ${ }^{6}$ However, there are few studies evaluating the cost of

\footnotetext{
${ }^{1}$ Specifically, our identified effect is about one tenths in size to that of a divorce or being widowed in Britain (Gardner and Oswald 2006), one tenths in size to a medium size lottery win in Britain (Gardner and Oswald 2007), 1/30 in size to the immigration from Tonga to New Zealand (Stillman et al. 2009), and 1/5-2/5 in size to the re-employment after involuntary job loss in the U.S. (Mandal and Roe 2008).

${ }^{2}$ One exception is Di Tella and MacCulloch (2008), which shows that sulfur oxide emissions may serve as one plausible explanation to the paradox.

${ }^{3}$ This approach complements the direct survey method to solicit people's WTP for improvement in air quality with a few advantages (Levinson 2012).

${ }^{4}$ Specifically, a $10 \mathrm{ppb}$ increase in ozone reduces farm worker productivity by 5.5 percent (or $\$ 700 \mathrm{M} / \mathrm{year}$ ) (Graff Zivin and Neidell 2012). A $10 \mu \mathrm{g} / \mathrm{m}^{3}$ rise in PM 2.5 inhibits manufacturing worker productivity by 6 percent (or $\$ 18 \mathrm{~B} / \mathrm{year}$ ) (Chang et al. 2016). A 10unit spike in API reduces office worker productivity by 0.35 percent (or $\$ 2.2 \mathrm{~B} / \mathrm{year}$ ) (Chang et al. 2014). An additional 10 units of transitory PM2.5 exposure is associated with a 1.64 unit decline in a student's high-stake exam score, a 0.15 decline in years of college education, and a $\$ 30$ decline in monthly salary (Ebenstein et al. 2016).

5 Air pollution may lead to more subtle effects, such as feeling gloomy and irritated with mild headaches (Chang et al. 2014; 2016), psychiatric distress (Rotton and Frey 1984), depressive symptoms (Szyszkowicz 2007), and eye irritations (Nattero and Enrico 1996).
} 
endemic air pollution on social welfare, especially in a developing setting. Besides, the condition of mental illness is much worse in low and middle income countries (LMIC) than in richer countries. ${ }^{7}$ Lack of research on the causes of depressive symptoms in LMICs is probably a reason. Our paper contributes to the literature by showing air pollution is a major risk factor of depressive symptoms in developing countries.

The remainder of the paper is organized as follows. Section 2 describes the data. Section 3 lays out the empirical strategy. Section 4 presents our main findings, including heterogeneous tests for potential mechanisms. Section 5 discusses implications for the Easterlin paradox and estimates the monetary cost of air pollution on happiness. Finally, section 6 concludes.

\section{Data}

\subsection{Mental Health and Subjective Well-being Measures}

We utilize rich measures of mental health and SWB in the China Family Panel Studies (CFPS), a nationally representative survey of Chinese communities, families, and individuals conducted in 2010, 2012, and 2014. The CFPS is funded by Peking University and carried out by the Institute of Social Science Survey of Peking University. The CFPS covers a wide range of domains for families and individuals from 162 counties in 25 provinces of China, including their economic activities, education outcomes, family dynamics and relationships, health, and SWB. ${ }^{8}$

There are four advantages of the CFPS for our purposes. First, information about geographic locations and dates of interviews for all respondents enables us to precisely match individual mental health and SWB measures in the survey with external air quality data. Second, rich measures ranging from moment-to-moment happiness and mental well-being to long-term life satisfaction allow us to compare the effects of air pollution in various time frames. Third, the longitudinal data allow us to remove unobserved individual factors that may bias the results. Fourth, the survey collected rich information at multiple levels, allowing us to control for a wide range of covariates.

We make use of three types of mental health and SWB measures. The first is life satisfaction (Welsch 2006, 2007; Rehdanz and Maddison 2008; MacKerron and Mourato 2009; Luechinger 2009, 2010; Menz 2011; Ferreira et al. 2013). All three waves of CFPS asked each respondent to answer the question, "Overall, how satisfied are you with your life?" on a scale from 1 (not satisfied at all) to 5 (very satisfied). With no specified time frame, life satisfaction, an evaluative measure of SWB, reflects the extent to which people's own

\footnotetext{
${ }^{6}$ For example, in year 2015 alone, Beijing had 288 days with 24-hour average PM2.5 level above $25 \mu \mathrm{g} / \mathrm{m}^{3}$, the WHO daily threshold for harmful effects on human beings. In India, Delhi's daily air pollution is above the WHO threshold for almost year around. ${ }^{7}$ LMIC populations have more than twice the rate of depressive symptoms, mood disorders, and anxiety disorders compared to their U.S. counterparts (U.S. Department of Health and Human Services 1999; Byers et al. 2010). The impact of depression on losing disability-adjusted life years (DALYs) in LMICs is more than four times larger than that in high-income countries (Mathers et al. 2008). Despite the staggeringly high costs, investment in mental illness prevention and treatment remains relatively low in LMICs (Collins et al. 2011).

${ }^{8}$ The CFPS uses multistage probability proportional to size sampling with implicit stratification to better represent Chinese society. The sample for the 2010 CFPS baseline survey is drawn through three stages (county, village, and household) from 25 provinces. The randomly chosen 162 counties largely represent Chinese Society (Xie and Hu 2014).
} 
experiences match their long-term aspirations and expectations about their lives as a whole (Stone and Mackie 2014). Life circumstances, such as income, education, and social status, are among the main determinants of life satisfaction. We reverse its response scale to indicate life dissatisfaction that is more comparable with other mental health and SWB measures.

The second mental health and SWB measure is the Center for Epidemiologic Studies Depression scale (CES-D) developed by Radloff (1977), a self-reported scale designed to measure the current level of depressive symptomatology in the general population.

Compared to life satisfaction, the CES-D highlights multidimensional emotional experiences that affect people in a shorter period. The CFPS 2010 and 2014 use a 6-item scale (Appendix B), which is highly correlated with the standard 20-item CES-D scale and has adequate psychometric properties for sensitive and specific detection of depressive disorders (Aggarwal et al. 2008). The five options for each item scale from 0 (never) to 4 (almost every day). Therefore, the total CES-D scores are valued between 0 and 24, with higher scores indicating more negative symptoms during the past month. Besides, we follow the Burnam screen to define a binary indicator for depressive symptoms with a cutoff of four (Burnam et al. 1988). ${ }^{9}$

The third SWB measure gauges short-term hedonic unhappiness. Respondents in the CFPS survey were asked to what extent they felt hard to cheer up in the past month, ranging from 0 (never) to 4 (almost every day). The higher the number, the unhappier the respondents were. Compared to life satisfaction, CES-D scores and hedonic unhappiness are more directly related to the environment and people's affective state in day-to-day and moment-to-moment life (Stone and Mackie 2014). ${ }^{10}$

\subsection{Interpolation of Weather and Pollution Measures}

We measure air quality using air pollution index (API) generated by a piecewise linear transformation from the concentrations of air pollutants, including sulfur dioxide $\left(\mathrm{SO}_{2}\right)$, nitrogen dioxide $\left(\mathrm{NO}_{2}\right)$, and fine particulate matter smaller than 10 micrometers (PM10). API ranges from 0 to 500, and a larger API value indicates worse air quality. Evidence suggests that fine particulate matter is detrimental to health and human capital (Cohen et al. 2005; Ebenstein et al. 2016) and is of high concentration in China (He, Liu, and Salvo 2016). Daily observations of API come from the city-level air quality report published by the Ministry of Environmental Protection of China. The report includes 86 major cities in 2000 and covers most of the cities in China in 2014 (Figure A1). ${ }^{11}$

We also include rich weather data in our analysis to help isolate the impact of air pollution from weather patterns. The weather data come from the National Climatic Data Center

\footnotetext{
${ }^{9}$ Note that each item in the standard CES-D scale ranges from 0 (never) to 3 (almost every day), rendering the standard binary depression indicator not perfectly comparable with that using CFPS given the same cut-off score. However, our findings are robust to using alternative CES-D cut-off scores. These results are available upon request.

${ }^{10}$ Hedonic well-being is closely related to the often-used terms "experienced well-being" and "emotional well-being." They are often used interchangeably in the literature.

${ }^{11}$ If the government indeed manipulates the API data when air quality is extremely bad as suggested by Chen et al. (2012) and Ghanem and Zhang (2014), using the official API data tends to underestimate the true impact of air pollution. Our estimates probably represent a lower bound.
} 
under the National Oceanic and Atmospheric Administration of the United States. The dataset contains records of rich weather conditions, such as temperature, precipitation, wind speed, and indicators for bad weather, ${ }^{12}$ on consecutive days from 402 monitoring stations in China. Besides, the sunshine duration data are obtained from the 194 monitoring stations of China National Meteorological Information Center. Sunshine may affect individuals' moods, social behavior, and health (Cunningham 1979; Wolfson 2013).

We match city-level API with CFPS samples in the following way. If a CFPS county is within an API reporting city, we use the city's API reading as the county's reading. If the county does not lie in any API cities, we use the API readings of the nearest available city within 40 kilometers according to the distance between the centroid of the CFPS county to the boundaries of nearby API reporting cities. ${ }^{13}$ In the robustness checks below, we also report results based on different cutoff radiuses. Following the convention of the literature (Levinson 2012), we use the radius of $40 \mathrm{~km}$ in our analyses to ensure precise match and retain greater number of observations. Meanwhile, we control for a weighted average of weather data for each CFPS county with weights based on the inverse distance to all monitors within a radius of $100 \mathrm{~km}$ of the CFPS county centroid. Both the binary indicator for bad weather and the sunshine duration are obtained from the nearest monitoring station.

For life dissatisfaction, we take advantage of an unbalanced panel of 33,612 individual respondents (or 88,263 observations) in CFPS 2010, 2012 and 2014, ${ }^{14}$ of which 57,591 observations could be matched to API and weather data. ${ }^{15}$ Due to some missing values for life dissatisfaction and household demographics, the final dataset for analyses includes 49,333 observations (or 23,400 individuals). Because six-item CES-D scale is only available in the 2010 and 2014 waves, we use a balanced panel of 23,259 individual respondents (or 46,518 observations) in the two waves for hedonic unhappiness and mental well-being. Among the 46,518 observations, 30,405 observations could be matched to API and weather data. There are some missing values for household demographics. The resulting dataset has 25,673 observations (or 16,271 individuals) for hedonic unhappiness and 25,593 observations (or 16,238 individuals) for mental well-being.

\section{Empirical Strategy}

Our baseline econometric specification is as follows:

$$
H_{\mathrm{ijt}}=\alpha P_{\mathrm{jt}}+\beta_{1} \ln Y_{\mathrm{ijt}}+\beta_{2} R_{\mathrm{ijt}}+X_{\mathrm{ijt}}^{\prime} r+W_{\mathrm{jt}}^{\prime} \varphi+\lambda_{i}+\delta_{j}+\eta_{i}+f(t)+\varepsilon_{\mathrm{ijt}}
$$

\footnotetext{
${ }^{12} \mathrm{Bad}$ weather includes fog, rain/drizzle, snow/ice pellets, hail, thunder, and tornadoes/funnel clouds.

${ }^{13} \mathrm{We}$ do not implement inverse distance weighting of air pollution index (API) as API depends nonlinearly on the level of local pollutants.

${ }^{14}$ The attrition rates for consecutive waves, i.e., 2010-2012 and 2012-2014, are 19.3\% and 13.9\%, respectively. We compare the attrition rate of CFPS with UK Household Longitudinal Survey (UKHLS). The two surveys conducted during the same period and followed similar interview methods, so UKHLS serves as a good benchmark of CFPS. Compared to UKHLS, CFPS' attrition rate is reasonable. In our baseline results, we also conduct repeated cross-sectional analyses to address the concern for attrition.

${ }^{15}$ Counties unmatched to any API reporting cities within $40 \mathrm{~km}$ or weather stations within $100 \mathrm{~km}$ are dropped. The matching rate $65.2 \%(=57,591 / 88,263)$ is higher than other studies. For example, one of the most comparable studies to us, Levinson (2012), is able to maintain $52.3 \%$ of the observations when matching the U.S. General Social Survey with PM10 readings from the EPA's Air Quality System.
} 
The dependent variable $H_{i j t}$ is mental health and SWB of respondent $i$ in county $j$ at date $t$. The key variable $P_{j t}$ is the air quality measure in county $j$ at date $t$. For income variables, we include both the $\log$ form of annual household per capita income $\ln Y_{i j t}$ and the self-rated relative income status $R_{i j t}$ ranging from 1 (lowest) to 5 (highest). Following the literature (Oswald 1997; Knight, Song, and Gunatilaka 2009; Knight and Gunatilaka 2010, 2011; Easterlin et al. 2012), we control for a set of demographic correlates of happiness $X_{i j t}$, including age and its square term, gender, marital status, years of education, unemployment status, party membership, and health status. We also control for a vector of rich weather conditions $W_{j}$, involving sunshine duration, mean temperature and its square term, total precipitation, mean wind speed, and a dummy for bad weather on the day of interview, to mitigate the concern that they are correlated with both mental health/SWB and air quality and therefore bias our estimations. $\lambda_{i}$ denotes individual fixed effect; $\delta_{j}$ represents county fixed effect; $\eta_{t}$ indicate month, year, and day-of-week fixed effects; $f(t)$ is the quadratic monthly time trend that ranges from 1 (January, 2010) to 60 (December, 2014) or the county-by-year fixed effect. $\varepsilon_{i j t}$ is the error term. Standard errors are clustered at the county level. Table 1 describes key variables and their summary statistics.

Figure A2 shows the distribution of interview dates for the three waves of the CFPS national sample, which span all months and seasons and thus enable us to isolate the impact of air pollution from seasonality. Overall, a majority of surveys were conducted in summer or winter as those seasons largely overlap with the summer vacation and winter break of the college students who implemented the CFPS. Variations for identification in our individual fixed effect model (equation 1) come from differential exposure to air pollution for the same respondent across the three waves. The average absolute change in API for each individual across waves amounts to 30 .

Before undertaking quantitative analyses, we plot the relationships between API and main mental health and SWB measures (Figure 1). We first calculate deviations from the withinindividual means for API and mental health/SWB measures and then graph the deviation of API against that of life dissatisfaction, hedonic unhappiness, and CES-D scores. As shown in Figure 1, in accordance with our expectation, hedonic unhappiness and CES-D scores demonstrate a positive relationship with API. However, the association between API and life dissatisfaction seems to be negative. Of course, these bivariate plots just provide suggestive evidence. More rigorous analyses are needed to control for other confounding factors.

\section{Results}

\subsection{Baseline Results}

We report baseline results of air pollution on various mental health and SWB measures in Panel A through Panel D of Table 2, respectively. To save space, only key variables are reported. The corresponding full estimation results are presented in Table A1 and Table A2. We add fixed effects step by step, and test several alternative specifications. Column (1) estimates a repeated cross-sectional specification to facilitate direct comparison with previous studies (e.g., Levinson (2012)). Columns (2) through (5) present longitudinal evidence with individual fixed effects. 
Panel A of Table 2 presents results on life dissatisfaction. Column (1) controls for demographic factors, weather, county fixed effects, quadratic time trend, and a full set of time fixed effects (i.e., year, month, and day-of-week). We do not find any significant relationship between API and life dissatisfaction. Both the absolute income and relative income are negatively correlated with life dissatisfaction. Consistent with the happiness literature, there is a U-shaped relationship between age and life satisfaction, and the trough of life satisfaction is around age 39 (Table A1). Men who are in poor health or divorced report lower life satisfaction. The coefficient for API remains insignificant in the longitudinal specification in column (2) when individual fixed effects are included. The pattern still holds when day-of-week fixed effects, quadratic time trend, rich weather conditions, and county-by-year fixed effects are further added in columns (3) through (5).

Overall, life satisfaction is immune from short-term air pollution. It is interesting to examine to what extent they are susceptible to long-term air pollution or more extreme air pollution as measured by greater deviations of current air pollution from its trends. Table A3 tests weekly, monthly, quarterly, half-year, one-year and two-year time trends, respectively. Life satisfaction remains insensitive to long-term air pollution and deviations from these trends. This muted impact might be explained by hedonic adaptation, a process that attenuates the long-term emotional impact of unfavorable circumstances. Hedonic adaptation may be evolutionarily optimal in protecting people from adverse mental reactions, saving energy on futile attempts to change the unchangeable and redirecting motivation to changes that can be made (Frederick and Loewenstein 1999). Over time, people may adjust their neutral reference point for the level of pollution upward. Future research is needed to directly test this hypothesis. ${ }^{16}$

Panel B of Table 2 examines air pollution on hedonic unhappiness. Higher API significantly increases hedonic unhappiness as shown in column (1). Married, educated, and healthier men tend to be happier. Moreover, the effect of API is larger and becomes more significant when individual fixed effects are controlled for as indicated in column (2). Under this longitudinal specification, relative income plays a highly significant role in affecting hedonic happiness, while absolute income does not. Columns (3) through (5) further control for the time trend and weather. Our main results remain robust to these additional controls.

In Panels $\mathrm{C}$ and $\mathrm{D}$ of Table 2, the CES-D scores and a binary measure of depressive symptoms (derived from the CES-D scores greater than four) are employed to measure mental health, respectively. Similar to hedonic unhappiness, results from both crosssectional and longitudinal specifications reveal that short-term air pollution worsens mental health and depressive symptoms.

\footnotetext{
${ }^{16}$ Another potential explanation for muted effect on life (dis)satisfaction may be the philosophical traditions in China and other East Asian countries emphasizing the dialectical nature of things as manifested in their religions, such as Buddhism and Daoism. As a result, East Asians often display a relatively high degree of equanimity in the face of negative emotions and events. For example, Rehdanz et al. (2015) find that people's assessments of the quality of their entire lives were not negatively affected even after being exposed to the tsunami and nuclear accident at Fukushima. Moreover, these philosophical traditions may also have a bearing on the way that people define life (dis)satisfaction. For example, Uchida and Kitayama (2009) show that East Asians and Americans who participated in an experiment regard happiness differently. However, this philosophical interpretation may not well explain why we find salient effects for shorter term measures of SWB.
} 
In Table 3, we estimate the non-linear effect of air pollution on mental health and SWB. According to the air quality standard published by the U.S. Environmental Protection Agency (EPA), we divide API into six categories, i.e., "Good" (API<50), "Moderate" (API in 51-100), "Unhealthy for Sensitive Groups" (API in 101-150), "Unhealthy" (API in 151200), "Very Unhealthy" (API in 201-300), and "Hazardous" (API>301). We assign each category a dummy variable and leave "Good" as the reference group. Figure A3 reveals the distribution of API with these cut-offs. The results in Table 3 show that the marginal effects increase significantly with the dose of exposure. Column (2) indicates that exposure to hazardous air pollution on the date of interview is associated with a 0.323 points increase in the hedonic unhappiness, more than triple the size of the effect for exposure to moderate air pollution.

If contemporary exposure to air pollution causes the decline in hedonic happiness and mental health, we should observe no effect of future air pollution on mental health and SWB elicited on the day of interview. As placebo tests, we control for the APIs in the forward 2-3 days simultaneously and repeat the previous analyses. ${ }^{17}$ As shown in Table A4, all the coefficients for forward APIs are statistically insignificant, suggesting that unobservable factors unlikely drive the association between contemporaneous air pollution and SWB.

The results so far use air quality measures obtained from API reporting cities within $40 \mathrm{~km}$. To address the concern for measurement errors and attenuation bias, Table A5 reports estimation results based on seven different cutoff radiuses ranging from $0 \mathrm{~km}$ to $60 \mathrm{~km}$. For example, Panel A of Table A5 reports regression results on a subsample including only respondents who live in API reporting cities (matching distance equals to zero). While in Panel G, the sample is expanded to include residents living within $60 \mathrm{~km}$ to the nearest API cities. The main findings hold no matter which radius is used, suggesting that measurement errors and attenuation bias do not affect our key findings.

The city-level APIs are computed based on readings in multiple monitoring stations. While we have access to the exact latitude and longitude information of all the monitoring stations in each API reporting city in 2014, the readings at the monitoring station level is not available in 2010. As another robustness check, we assign the reported city-level APIs in 2010 to all stations within the city boundary and match CFPS counties to the nearest air quality monitoring station within a specific radius. Our results are robust to various radiuses between 40 and $90 \mathrm{~km}$. The results are available upon request.

\subsection{Heterogeneous Effects}

We observe heterogeneous effect of air pollution on happiness and mental health. First, the effect may vary by gender and age. Columns (1) through (5) in Table 4 present the impact of air pollution by gender and age cohort, respectively. Table A6 further shows the impact by gender and age cohort combined. Results indeed suggest that young adults respond more strongly to air pollution than elderly. There are several possible explanations. First, older people are probably more accustomed to living in the dirty air. Second, young people spend

${ }^{17}$ Since air quality today can be highly correlated with air quality tomorrow, we exclude 1-day forward API to make sure we achieve clean identifications in these placebo tests. 
more time outdoors than senior people. Third, young people are likely more informed of air quality thanks to wide access to smart phones and the Internet, therefore paying more attention to air pollution. In addition, we find that men and women respond to air pollution differently in accordance with the finding of Ebenstein et al. (2016). Interestingly, gender differences vary with the choice of outcome variables. Specifically, men's hedonic happiness is more sensitive to air pollution, while women's mental health is more saliently affected. ${ }^{18}$

Furthermore, vulnerable populations, including those of lower income, less educated, working outdoors, living in more polluted areas, are more susceptible to air pollution. Grouping respondents by income quintile, results in Columns (1) through (4) of Table 5 show that the rich are less affected, presumably because they can take some preventive actions, such as installing air purifiers at home, to mitigate the harmful effects of air pollution. Columns (5) through (6) of Table 5 indicate that those who did not finish nineyear mandatory education are affected more. Results presented in Columns (1) through (2) of Table 6 confirm that air pollution imposes larger impact on hedonic happiness of people working outdoors, though recent evidence suggests that outdoor air pollution even reduce indoor worker productivity (Chang et al. 2014, 2016; He, Liu, and Salvo 2016). People living in more polluted areas could be more (or less) sensitive to air pollution than those in less polluted areas, depending on whether the dose-response relationship (or habituation or self-selection into areas of poor air quality) dominates. Separating the sample by the median level of average API in the past four years, results in Columns (3) through (4) of Table 6 show that the effects of air pollution are graver in more polluted areas, indicating that the dose-response relationship may dominate.

Lastly, results in the last two columns of Table 6 show that families with young children (under age 16 in 2014) are more emotionally vulnerable in mental health to air pollution.

\section{Implications for the Easterlin Paradox}

Following the seminal work of Easterlin $(1974,1995)$, there has been a growing literature explaining the happiness puzzle, also known as the Easterlin paradox. ${ }^{19}$ Concern for relative income has been regarded as the most plausible explanation for the paradox (Luttmer 2005; Clark, Frijters, and Shields 2008; Chen 2015b). ${ }^{20}$ We are among the first to simultaneously evaluate the economic significance of air pollution, relative income, and other correlates in explaining the stagnant or even declining happiness trend. Following Di Tella and MacCulloch (2008), our results suggest air pollution as an additional important contributor to the Easterlin paradox, which has been largely ignored in the literature.

\footnotetext{
18 Following Menz and Welsch (2012), we examine potential life-cycle and birth-cohort effects by adding the interaction terms of age cohort or birth cohort with API into main regressions. Regarding life-cycle effects, none of the coefficients for the interaction terms is significant. Similarly, the difference across birth cohorts is largely insignificant except that the oldest cohort (born before 1930) reported higher rate of depressive symptoms. There is still no statistical difference across cohorts after controlling for both life-cycle and birth-cohort effects. This consistent pattern of birth cohort effects and life-cycle effects underscores the validity of using SWB measures for an assessment of air pollution effects. The results are available upon request.

${ }^{19}$ Several empirical studies (Hagerty and Veenhoven 2003; Stevenson and Wolfers 2008) based on cross-country data dismiss the paradox. Drawing an updated database of 37 countries, Easterlin et al. (2010) reconfirm the paradox. Despite the controversial crosscountry evidence, the paradox has been observed in a number of major economies (Tella and MacCulloch 2006; Easterlin et al. 2012). ${ }^{20}$ Other plausible driving forces include the framing of happiness questions (Graham, Chattopadhyay, and Picon 2010), income measurement errors (Graham, Chattopadhyay, and Picon 2010), and omitted factors (for example, social trust and freedom) (Helliwell 2012; Inglehart et al. 2008).
} 
China provides an ideal case to study the Easterlin paradox. In spite of unprecedented income growth, China's average happiness measures did not improve from 1990 to 2010 (Easterlin et al. 2012). Life satisfaction (scaled from 1, dissatisfied, to 10, satisfied) and hedonic happiness (scaled from 1, not at all happy, to 4, very happy) from the World Value Survey, and happiness (scaled from 1, very unhappy, to 5, very happy) from the China Central Television (CCTV) Postcard Survey all reveal an obvious pattern of stagnant or even declined happiness in China during the past decades (Table A7). For example, the CCTV survey finds that the proportion of people feeling happy or very happy declined from 54.1 percent to 40.6 percent between 2007 and 2014, while the share of people reporting unhappy or very unhappy rose from 7.6 percent to 15.3 percent (Figure A4).

Easterlin et al. (2012) attribute the Chinese happiness puzzle to a high unemployment rate due to state-owned enterprise (SOE) reforms, the dissolution of the social safety net, and rising inequality throughout the 1990s and the early 2000s. These factors may explain the temporal pattern from 1990 through 2007, but they cannot account for the decline in happiness during 2007 through 2014, as all these indicators were improved in the period. The SOE reforms were finished by the late 1990s. Since 2004, the labor market has become tighter, resulting in lower unemployment rates and more rapid increases in real wages (Zhang, Yang, and Wang 2011; Zhang et al. 2014). Along with lower unemployment rates and rising wages, the Gini coefficient for China as a whole has declined since 2008 (Xie et al. 2013). Moreover, more social safety nets have been put in place in the past decade. For example, the new rural cooperative medical scheme has been rolled out rapidly since 2003 (Li, Xia, and Yu 2014), and the new rural pension program has been rolled out since 2009 (Chen 2015a). The evidence suggests additional factors must be at play.

Similar to Easterlin (1974), we also find a noticeable positive association between absolute income and happiness across individuals within a county at a given point of time (Column (1) of Panel B in Table 2), but the association disappears when individual fixed effects are controlled for to compare within each individual over waves of the longitudinal survey (Column (4) of Panel B in Table 2). By comparison, relative income affects hedonic happiness both at a point of time and over time, confirming relative income as a plausible explanation to the Easterlin paradox.

More interestingly, our results also show worsening air quality as an additional driving force of the observed decline in happiness. According to the World Bank, 16 of the world's top 20 most polluted cities are in China. ${ }^{21}$ The report published by China's Ministry of Environmental Protection in June 2013 shows that about 60 percent of 325 prefecture-level cities failed to meet the Ambient Air Quality Standards (GB3095-2012) in 2012. ${ }^{22}$ Almost half of the Chinese population is exposed to PM2.5 at a level beyond the highest hazard threshold in the United States (The Economist 2015).

Based on a back-of-the-envelope calculation using results in Column (4) of Panel B in Table 2, a one SD decrease in API lifts happiness by 0.034 (equivalent to $0.036 \mathrm{SDs}$ ). The impact

${ }^{21}$ See www.cbsnews.com/news/the-most-polluted-places-on-earth/, citing “The Little Green Data Book” (World Bank, May 2007, ISBN 0-8213-6967-9).

${ }^{22}$ See www.zhb.gov.cn/gkml/hbb/qt/201306/t20130604_253201.htm. 
is rather sizable considering that a one SD increase in income status, one of the most important predictors of happiness, raises happiness by 0.039 (equivalent to $0.042 \mathrm{SDs}$ ). ${ }^{23} \mathrm{In}$ the CCTV Postcard Survey, self-reported happiness declined by 0.326 SDs (measured by the SD in 2014) from 2007 to 2014. The 37.132 units or 2.036-standard-deviation (measured by the SD in 2014) increase in population-weighted annual mean API during the same period accounts for 22.5 percent of the actual decrease in happiness. ${ }^{24}$

Finally, we assess the money metric value of air quality based on the repeated crosssectional results in Column (1) of Panel B in Table 2. The coefficient on API indicates that a one-unit increase in API leads to a decline in happiness by $0.044 \%$, while the coefficient on $\log$ per capita income shows that a $1 \%$ increase in annual household per capita income raises happiness by $0.022 \%$. According to a back-of-the-envelope calculation, people are on average willing to pay $2.0 \%$ of their annual income for a one-unit reduction in API on the day of the interview. By totally differentiating equation (1) and holding hedonic happiness constant (i.e., setting $d H=0$ ), we calculate the average marginal rate of substitution between air quality and absolute income $\partial Y /\left.\partial P\right|_{d H=0}=-\mathrm{Ya} / \hat{\beta}_{1}$, also known as willingness to pay (WTP). Plugging in $0.044 \%$ for $\hat{a},-0.022$ for $\hat{\beta}, 12913.82$ for the mean annual household per capita income (in Chinese yuan), WTP corresponds to $\partial Y / \partial P=¥ 258$, which indicates that a one-unit decline in API raises an average person’s happiness by an amount worth $¥ 258$ (\$42) per year per person, or $¥ 0.71$ per day per person. ${ }^{25}$ To put this into context, note that the SD of API is 36.474 . The WTP amounts to $¥ 26$ (=36.474x¥0.71) for a one SD decline in API per day. In other words, people are on average willing to pay $¥ 26$ (\$4.23) per day for a one SD improvement in air quality. ${ }^{26}$

Our estimated absolute level of WTP for the Chinese population is much smaller than that for the U.S. population, such as $\$ 35$ (or $¥ 215$ ) for a one SD reduction per day per person (Levinson 2012). However, if measured as the share of annual household per capita income, Chinese are willing to pay an equal share of their annual income ( 2.0 percent) to reduce air pollution with their U.S. counterparts (2.1 percent).

\section{Conclusion}

This paper estimates the impact of day-to-day air quality on long-term life satisfaction, short-term hedonic happiness, and mental well-being by matching self-reported mental and SWB measures in CFPS, a nationally representative survey, with air quality data according to the exact date and place of the interview. Although bad daily air quality does not affect much overall life satisfaction, it lowers hedonic happiness and raises the rate of depressive symptoms. In particular, people who are more concerned with environmental problems,

\footnotetext{
${ }^{23}$ All the summary statistics are calculated using the sample in Column (4) of Panel B in Table 2, i.e. Mean (hedonic unhappiness) = $0.722, \mathrm{SD}$ (hedonic unhappiness $)=0.932 ;$ Mean $(\mathrm{API})=76.370, \mathrm{SD}(\mathrm{API})=36.055 ;$ Mean (relative income $)=2.366, \mathrm{SD}$ (relative income $)=0.982$.

${ }^{24}$ The spike in API from 2012 to 2014 (as shown in Table 1) is probably more associated with the massive stimulus package by the Chinese government after the global financial crisis in the late 2000s. Most of the stimulus package went to the infrastructure and construction sector which has accelerated since 2010, mirroring the jump of API in the same period.

$25 ¥ 258$ corresponds to $\$ 42$ using the average 2014 exchange rate 1 USD $=6.1434 \mathrm{CNY}$.

${ }^{26}$ To address the potential endogeneity problem of the income variable, following Levinson (2012), we instrument household income by occupation-specific average income at the provincial level in the same year using 2SLS regression. The main finding still holds. The results are available upon request.
} 
work outdoors, earn lower incomes, reside in less polluted areas, or have young children are more sensitive to air pollution.

Our paper shows worsening air quality may contribute to the Easterlin paradox and render significant monetary cost associated with decline in happiness. The impact of air quality on happiness is only slightly smaller than that of relative income, the commonly regarded key contributor to the paradox. The findings suggest that the GDP-obsessed development strategy in China has not brought about improved happiness.

Furthermore, evaluating a wider spectrum of the impact of air pollution provides useful information for public policies. Our results indicate that the current emphasis on physical health related costs understates other hidden costs of pollution on mental health and SWB. If counting these additional costs, the benefits of reducing pollution would be higher.

\section{Supplementary Material}

Refer to Web version on PubMed Central for supplementary material.

\section{References}

Aggarwal A, Freund K, Sato A, Adams-Campbell L, Lopez A, Lessin L, Ockene J, Wallace R, Williams C, Bonds D. Are Depressive Symptoms Associated with Cancer Screening and Cancer Stage at Diagnosis among Postmenopausal Women? Journal of Women's Health. 2008; 17(8):13531361 .

Beatty TMK, Shimshack JP. Air Pollution and Children's Respiratory Health: A Cohort Analysis. Journal of Environmental Economics and Management. 2014; 67:39-57.

Byers AL, Yaffe K, Covinsky KE, Friedman MB, Bruce ML. High occurrence of mood and anxiety disorders among older adults: The National Comorbidity Survey Replication. Arch Gen Psychiatry. 2010; 67:489-96. [PubMed: 20439830]

Burnam MA, Wells KB, Leake B, Landsverk J. Development of a brief screening instrument for detecting depressive disorders. Med Care. 1988; 26:775-789. [PubMed: 3398606]

Chang T, Graff Zivin J, Gross T, Neidell M. The Effect of Pollution on Office Workers: Evidence from Call Center Workers in China. NBER Working Paper No. 22328. 2014

Chang T, Graff Zivin J, Gross T, Neidell M. Particulate Pollution and the Productivity of Pear Packers. American Economic Journal: Economic Policy. 2016; 8(3):141-169.

Chen X. Old Age Pension and Intergenerational Living Arrangements: A Regression Discontinuity Design. Review of Economics of the Household. 2015a; 13:1-22.

Chen X. Relative Deprivation and Individual Well-being: Health, Human Capital and Happiness. IZA World of Labor. 2015b; 140:1-10.

Chen Y, Ebenstein A, Greenstone M, Li H. Evidence on the Impact of Sustained Exposure to Air Pollution on Life Expectancy from China's Huai River Policy. PNAS. 2013; 110:12936-12941. [PubMed: 23836630]

Chen Y, Jin GZ, Kumar N, Shi G. Gaming in Air Pollution Data? Lessons from China. B.E. Journal of Economic Analysis \& Policy. 2012; 13(3):1-43.

Clark AE, Frijters P, Shields MA. Relative Income, Happiness, and Utility: An Explanation for the Easterlin Paradox and Other Puzzles. Journal of Economic Literature. 2008; 46:95-144.

Cohen AJ, Ross Anderson H, Ostro B, Pandey KD, Krzyzanowski M, Künzli N, Gutschmidt K, Pope A, Romieu I, Samet JM, Smith K. The Global Burden of Disease due to Outdoor Air Pollution. Journal of Toxicology and Environmental Health, Part A: Current Issues. 2005; 68(13/14):13011307. 
Collins PY, Patel V, Joestl SS, March D, Insel TR, Daar AS, Bordin IA, Costello EJ, Durkin M, Fairburn C, et al. Grand challenges in global mental health. Nature. 2011; 475(7354):27-30. [PubMed: 21734685]

Cunningham MR. Weather, Mood, and Helping Behavior: Quasi Experiments with the Sunshine Samaritan. Journal of Personality and Social Psychology. 1979; 37(11):1947-1956.

Deaton A, Stone AA. Two Happiness Puzzles. American Economic Review. 2013; 103:591-597. [PubMed: 25110356]

Deaton A, Lubotsky D. Mortality, Inequality and Race in American Cities and States. Social Science \& Medicine. 2003; 56:1139-1153. [PubMed: 12600354]

Di Tella R, MacCulloch R. Some Uses of Happiness Data in Economics. Journal of Economic Perspectives. 2006; 20(1):25-46.

Di Tella R, MacCulloch R. Gross National Happiness as an Answer to the Easterlin Paradox? Journal of Development Economics. 2008; 86:22-42.

Easterlin, RA. Does Economic Growth Improve the Human Lot? Some Empirical Evidence. In: David, PA., Reder, MW., editors. Nations and Households in Economic Growth. New York: Academic Press; 1974.

Easterlin RA. Will Raising the Incomes of All Increase the Happiness of All? Journal of Economic Behavior and Organization. 1995; 27:35-47.

Easterlin RA, Angelescu McVey L, Switek M, Sawangfa O, Smith Zweig J. The Happiness-income Paradox Revisited. PNAS. 2010; 107(52):22463-22468. [PubMed: 21149705]

Easterlin RA, Morgan R, Switek M, Wang F. China's Life Satisfaction, 1990-2010. PNAS. 2012; 109:9775-9780. [PubMed: 22586096]

Ebenstein A, Lavy V, Roth S. The Long-Run Economic Consequences of High-Stakes Examinations: Evidence from Transitory Variation in Pollution. American Economic Journal: Applied Economics. 2016; 8(4):36-65.

Ferreira S, Akay A, Brereton F, Cuñado J, Martinsson P, Moro M, Ningal TF. Life Satisfaction and Air Quality in Europe. Ecological Economics. 2013; 88:1-10.

Frederick, S., Loewenstein, G. Hedonic Adaptation. In: Kahneman, D.Diener, E., Schwarz, N., editors. Scientific Perspectives on Enjoyment, Suffering, and Well-being. New York, US: Russell Sage Foundation; 1999. p. 302-329.

Gallagher P, Lazarus W, Shapouri H, Conway R, Bachewe F, Fischer A. Cardiovascular Disease-Risk Benefits of Clean Fuel Technology and Policy: A Statistical Analysis. Energy Policy. 2010; 38:1210-1222.

Gardner J, Oswald AJ. Do Divorcing Couples Become Happier by Breaking up? Journal of the Royal Statistical Society, Series A (Statistics in Society). 2006; 169(2):319-336.

Gardner J, Oswald AJ. Money and Mental Well-being: A Longitudinal Study of Medium-sized Lottery Wins. Journal of Health Economics. 2007; 26(1):49-60. [PubMed: 16949692]

Ghanem D, Zhang J. Effortless Perfection': Do Chinese Cities Manipulate Air Pollution Data? Journal of Environmental Economics and Management. 2014; 68:203-225.

Graff Zivin J, Neidell M. The Impact of Pollution on Worker Productivity. American Economic Review. 2012; 102(7):3652-3673. [PubMed: 26401055]

Graham C. The economics of happiness. World Economy. 2005; 6(3):41-55.

Graham, C., Chattopadhyay, S., Picon, M. The Easterlin and Other Paradoxes: Why Both Sides of the Debate May Be Correct?. In: Diener, E.Kahneman, D., Helliwell, J., editors. International Differences in Well-being. Oxford, UK: Oxford University Press; 2010. p. 247-290.chap. 9

Greenstone M, Hanna R. Environmental Regulations, Air and Water Pollution, and Infant Mortality in India. American Economic Review. 2014; 104(10):3038-3072.

Hagerty MR, Veenhoven R. Wealth and Happiness Revisited-Growing National Income Does Go with Greater Happiness. Social Indicators Research. 2003; 64(1):1-27.

He, Jiaxiu, Liu, Haoming, Salvo, Alberto. Severe Air Pollution and Labor Productivity: Evidence from Industrial Towns in China. IZA Discussion Paper 8916. 2016

Helliwell, J. NBER Working Paper 18486. Cambridge, MA, US: National Bureau of Economic Research; 2012. Understanding and Improving the Social Context of Well-being. 
Inglehart R, Foa R, Peterson C, Welzel C. Development, Freedom, and Rising Happiness: A Global Perspective (1981-2007). Perspectives on Psychological Science. 2008; 3(4):264-285. [PubMed: 26158947]

Jayachandran S. Air Quality and Early-Life Mortality: Evidence from Indonesia's Wildfires. Journal of Human Resources. 2009; 44(4):916-954.

Kahneman D, Deaton A. High Income Improves Evaluation of Life but Not Emotional Well-being. PNAS. 2010; 107:16489-16493. [PubMed: 20823223]

Knight J, Gunatilaka R. The Rural-urban Divide in China: Income but Not Happiness? Journal of Development Studies. 2010; 46:506-534.

Knight J. Does Economic Growth Raise Happiness in China? Oxford Development Studies. 2011; 39:1-24.

Knight J, Song L, Gunatilaka R. Subjective Well-being and Its Determinants in Rural China. China Economic Review. 2009; 20:635-649.

Levinson A. Valuing Public Goods Using Happiness Data: The Case of Air Quality. Journal of Public Economics. 2012; 96:869-880.

Levinson A. Happiness, Behavioral Economics, and Public Policy. NBER Working Papers 19329. 2013

Li, J., Xia, C., Yu, X. Jiating Yiliao Zhichu yu Fudan. In: Xie, Y.Zhang, X., Li, J., editors. China Minsheng Fazhan Baogao. Zurich, Switzerland: Peking University Press; 2014. chap. 6

Lleras-Muney A. The Needs of the Army: Using Compulsory Relocation in the Military to Estimate the Effect of Air Pollutants on Children's Health. Journal of Human Resources. 2010; 45(3):549590.

Luechinger S. Valuing Air Quality Using the Life Satisfaction Approach. Economic Journal. 2009; 119:482-515.

Luechinger S. Life Satisfaction and Transboundary Air Pollution. Economics Letters. 2010; 107:4-6.

Luttmer E. Neighbors as Negative: Relative Earnings and Well-being. Quarterly Journal of Economics. 2005; 120(3):963-1002.

MacKerron G, Mourato S. Life Satisfaction and Air Quality in London. Ecological Economics. 2009; 68:1441-1453.

Manda B, Roe B. Job Loss, Retirement and the Mental Health of Older Americans. Journal of Mental Health Policy and Economics. 2008; 11:167-176. [PubMed: 19096091]

Mathers, CD., Fat, DM., Boerma, J. The global burden of disease: 2004 update. World Health Organization; 2008.

Menz T. Do People Habituate to Air Pollution? Evidence from International Life Satisfaction Data. Ecological Economics. 2011; 71:211-219.

Menz T, Welsch H. Life-Cycle and Cohort Effects in the Valuation of Air Quality: Evidence from Subjective Well-being Data. Land Economics. 2012; 88(2):300-325.

Moretti E, Neidell M. Pollution, health, and avoidance behavior: Evidence from the ports of Los Angeles. Journal of Human Resources. 2011; 46(1):154-175.

Nattero, Giovanni, Annalisa, Enrico. Outdoor Pollution and Headache. Headache. 1996; 36:243-245. [PubMed: 8675430]

Neidell M. Information, Avoidance Behavior, and Health: The Effect of Ozone on Asthma Hospitalizations. Journal of Human Resources. 2009; 44(2):450-478.

Oswald AJ. Happiness and Economic Performance. Economic Journal. 1997; 107:1815-1831.

Radloff LS. The CES-D Scale: A Self-report Depression Scale for Research in the General Population. Applied Psychological Measurement. 1977; 1:385-401.

Rehdanz K, Maddison D. Local Environmental Quality and Life-satisfaction in Germany. Ecological Economics. 2008; 64:787-797.

Rehdanz K, Welsch H, Narita D, Okubo T. Well-being effects of a major natural disaster: The case of Fukushima. Journal of Economic Behavior \& Organization. 2015; 116(C):500-517.

Rotton J, Frey J. Psychological Costs of Air Pollution: Atmospheric Conditions, Seasonal Trends, and Psychiatric Emergencies. Population and Environment. 1984; 7(1):3-16. 
Stevenson, B., Wolfers, J. Economic Growth and Subjective Well-being: Reassessing the Easterlin Paradox. NBER Working Paper 14282. Cambridge, MA, US: National Bureau of Economic Research; 2008.

Stillman S, McKenzie D, Gibson J. Migration and Mental Health: Evidence from a Natural Experiment. Journal of Health Economics. 2009; 28(3):677-687. [PubMed: 19349087]

Stone, AA., Mackie, C., editors. Subjective Well-being: Measuring Happiness, Suffering, and Other Dimensions of Experience. Washington, DC: National Research Council, National Academies Press; 2014.

Szyszkowicz, Mieczysław. Air Pollution and Emergency Department Visits for Depression in Edmonton, Canada. International Journal of Occupational Medicine and Environmental Health. 2007; 20(3):241-245. [PubMed: 17932013]

Tanaka S. Environmental Regulations on Air Pollution in China and Their Impact on Infant Mortality. Journal of Health Economics. 2015; 42:90-103. [PubMed: 25868145]

The Economist. Mapping the Invisible Scourge. 2015 Aug 15.

U.S. Department of Health and Human Services. Mental Health: A Report of the Surgeon General. Rockville, MD: U.S. Department of Health and Human Services, Substance Abuse and Mental Health Services Administration, Center for Mental Health Services, National Institutes of Health, National Institute of Mental Health; 1999.

Uchida Y, Kitayama S. Happiness and unhappiness in East and West: themes and variations. Emotion. 2009; 9:441-456. [PubMed: 19653765]

Welsch H. Environment and Happiness: Valuation of Air Pollution Using Life Satisfaction Data. Ecological Economics. 2006; 58:801-813.

Welsch H. Environmental Welfare Analysis: A Life Satisfaction Approach. Ecological Economics. 2007; 62:544-551.

Wolfson E. Your Zodiac Sign, Your Health. The Atlantic. 2013 Nov 15.

Xie Y, Hu J. An introduction to the China Family Panel Studies (CFPS). Chinese Sociological Review. 2014; 47(1):3-29.

Xie, Y., Zhang, X., Xu, Q., Zhang, C. Shouru Fenpei. In: Xie, Y.Zhang, X., Li, J., editors. China Minsheng Fazhan Baogao. Zurich, Switzerland: Peking University Press; 2013. chap. 2

Zhang C, Xu Q, Zhou X, Zhang X, Xie Y. Are Poverty Rates Underestimated in China? New Evidence from Four Recent Surveys. China Economic Review. 2014; 31:410-425.

Zhang X, Yang J, Wang S. China Has Reached the Lewis Turning Point. China Economic Review. 2011; 22(4):542-554.

J Environ Econ Manage. Author manuscript; available in PMC 2018 September 01. 

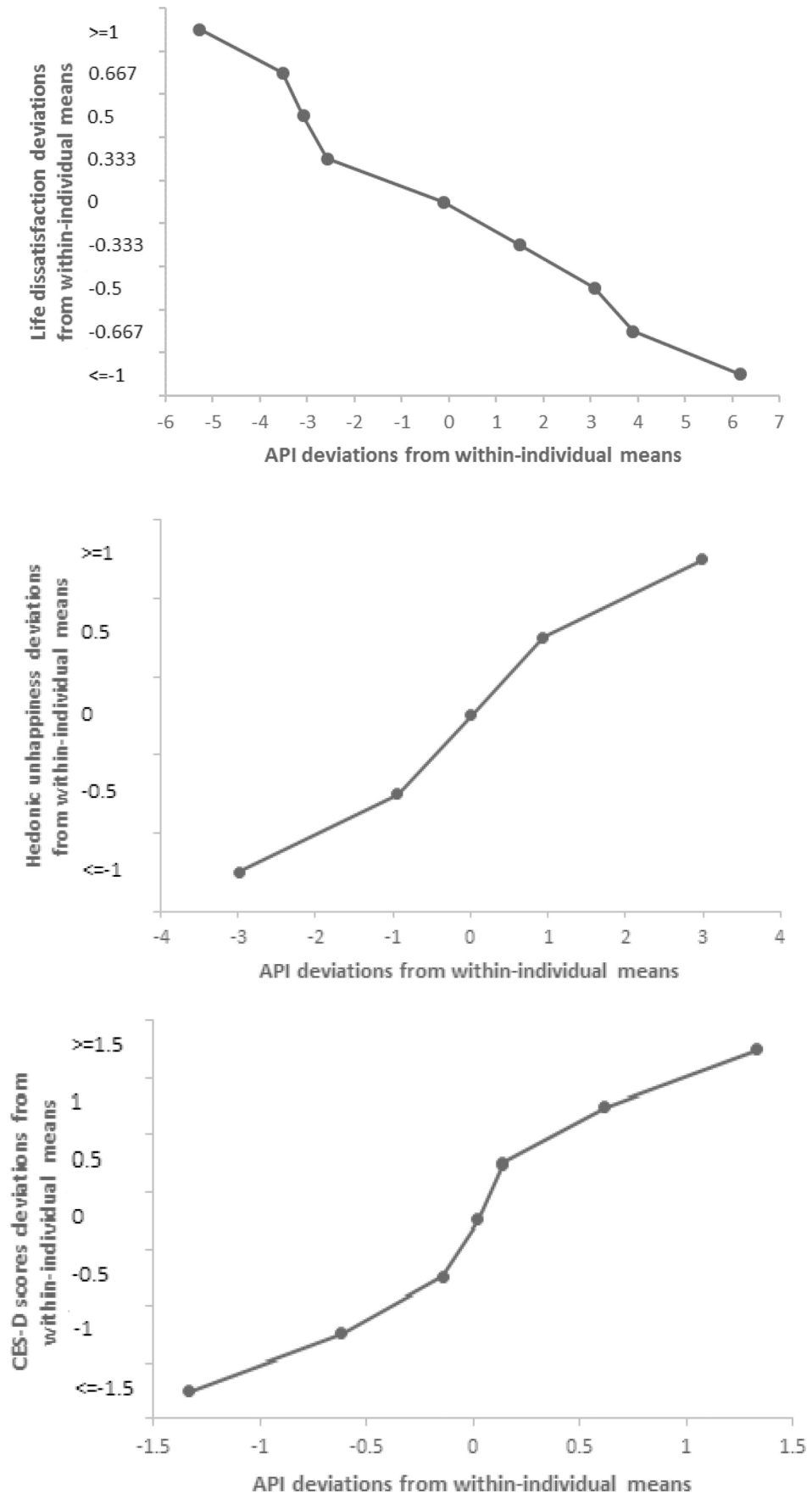

Figure 1. Relationship between API and mental health \& subjective well-being Source: China Family Panel Studies 2010, 2012 and 2014.

Note: API $=$ air pollution index. CES-D = Center for Epidemiologic Studies Depression scale. 


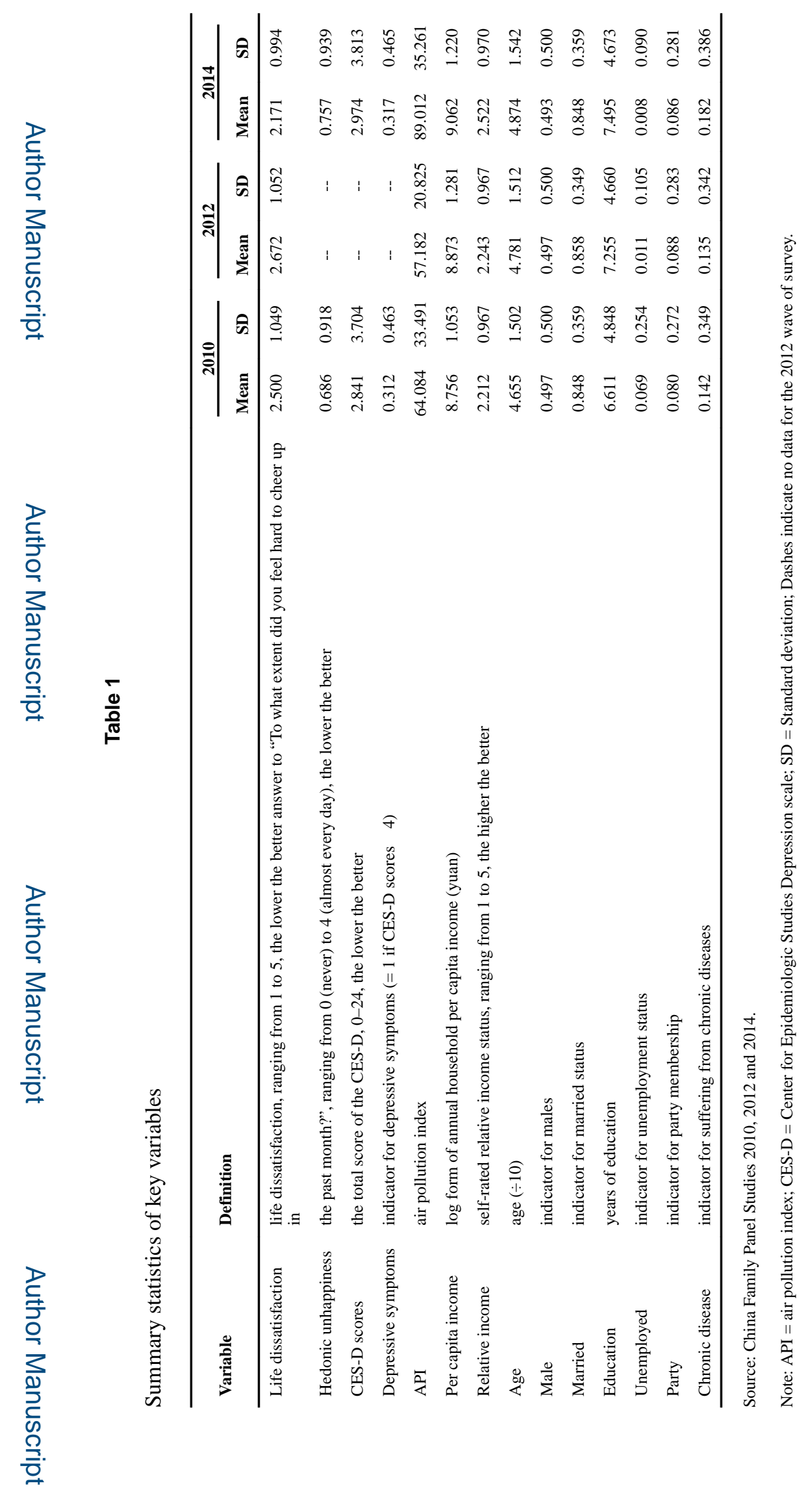

J Environ Econ Manage. Author manuscript; available in PMC 2018 September 01. 


\section{를 \\ 일}

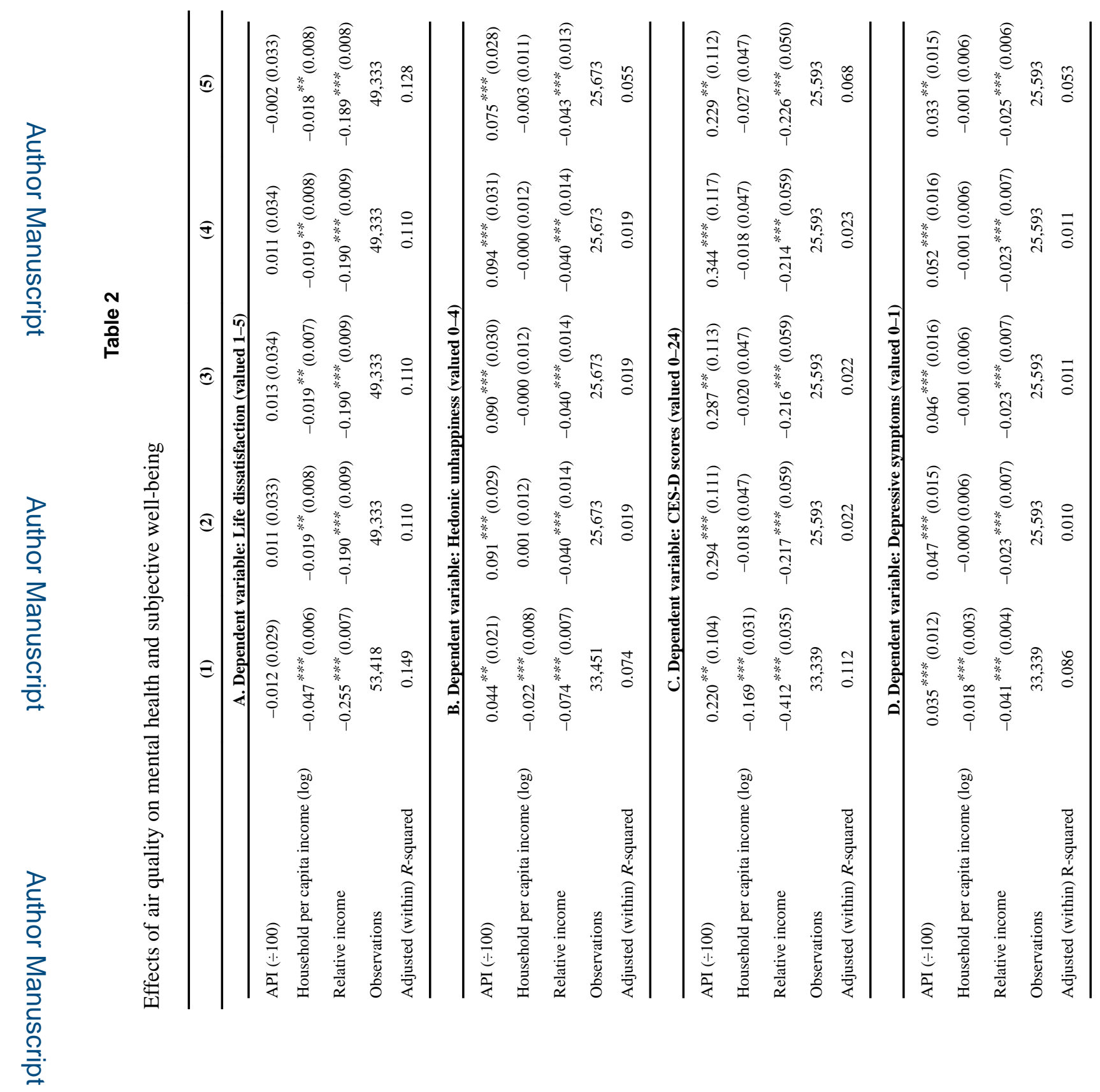

J Environ Econ Manage. Author manuscript; available in PMC 2018 September 01. 


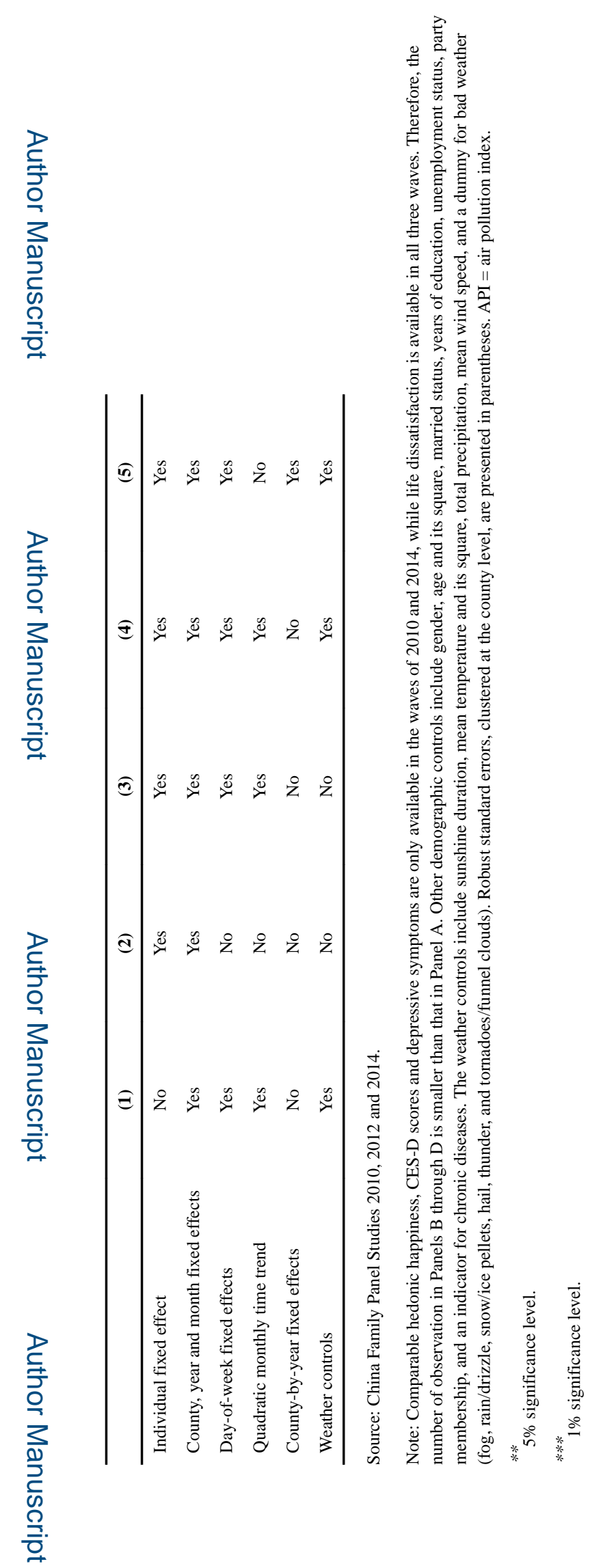

J Environ Econ Manage. Author manuscript; available in PMC 2018 September 01. 
Table 3

Nonlinear effects of air quality on mental health and subjective well-being

\begin{tabular}{|c|c|c|c|c|}
\hline Dependent variable & $\frac{\text { Life dissatisfaction }}{\text { (1) }}$ & $\frac{\text { Hedonic unhappiness }}{\text { (2) }}$ & $\frac{\text { Mental well-being }}{\text { (3) }}$ & $\frac{\text { Depressive symptoms }}{\text { (4) }}$ \\
\hline API51_100 & $0.000(0.018)$ & $0.077^{* *}(0.038)$ & $0.350 *(0.191)$ & $0.029(0.022)$ \\
\hline API101_50 & $-0.004(0.029)$ & $0.118^{* *}(0.046)$ & $0.595^{* * *}(0.215)$ & $0.070^{* * *}(0.026)$ \\
\hline API151_200 & $0.007(0.064)$ & $0.221^{* *}(0.086)$ & $1.040^{* * *}(0.331)$ & $0.119^{* * *}(0.039)$ \\
\hline API201_00 & $0.065(0.083)$ & $0.277^{* *}(0.109)$ & $0.502(0.460)$ & $0.112^{* *}(0.053)$ \\
\hline API301_500 & $-0.136(0.271)$ & $0.323^{* *}(0.133)$ & $1.378^{* * *}(0.511)$ & $0.199^{* *}(0.084)$ \\
\hline Household per capita income $(\log )$ & $-0.020^{* *}(0.008)$ & $-0.000(0.012)$ & $-0.017(0.047)$ & $-0.001(0.006)$ \\
\hline Relative income & $-0.190^{* * *}(0.009)$ & $-0.040^{* * * *}(0.014)$ & $-0.215^{* * *}(0.059)$ & $-0.023^{* * *}(0.007)$ \\
\hline Individual fixed effect & Yes & Yes & Yes & Yes \\
\hline County, year and month fixed effects & Yes & Yes & Yes & Yes \\
\hline $\begin{array}{l}\text { Day-of-week fixed effects, quadratic time } \\
\text { trend }\end{array}$ & Yes & Yes & Yes & Yes \\
\hline Weather controls & Yes & Yes & Yes & Yes \\
\hline Number of observations & 49,333 & 25,673 & 25,593 & 25,593 \\
\hline Adjusted (within) R-squared & 0.110 & 0.020 & 0.025 & 0.012 \\
\hline
\end{tabular}

Source: China Family Panel Studies 2010, 2012 and 2014.

Note: All other covariates follow Table 2. Robust standard errors, clustered at the county level, are presented in parentheses. API = air pollution index.

* $10 \%$ significance level.

*** significance level.

**** $1 \%$ significance level.

J Environ Econ Manage. Author manuscript; available in PMC 2018 September 01. 


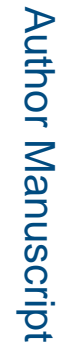

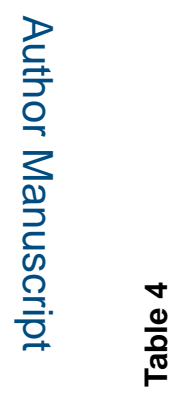

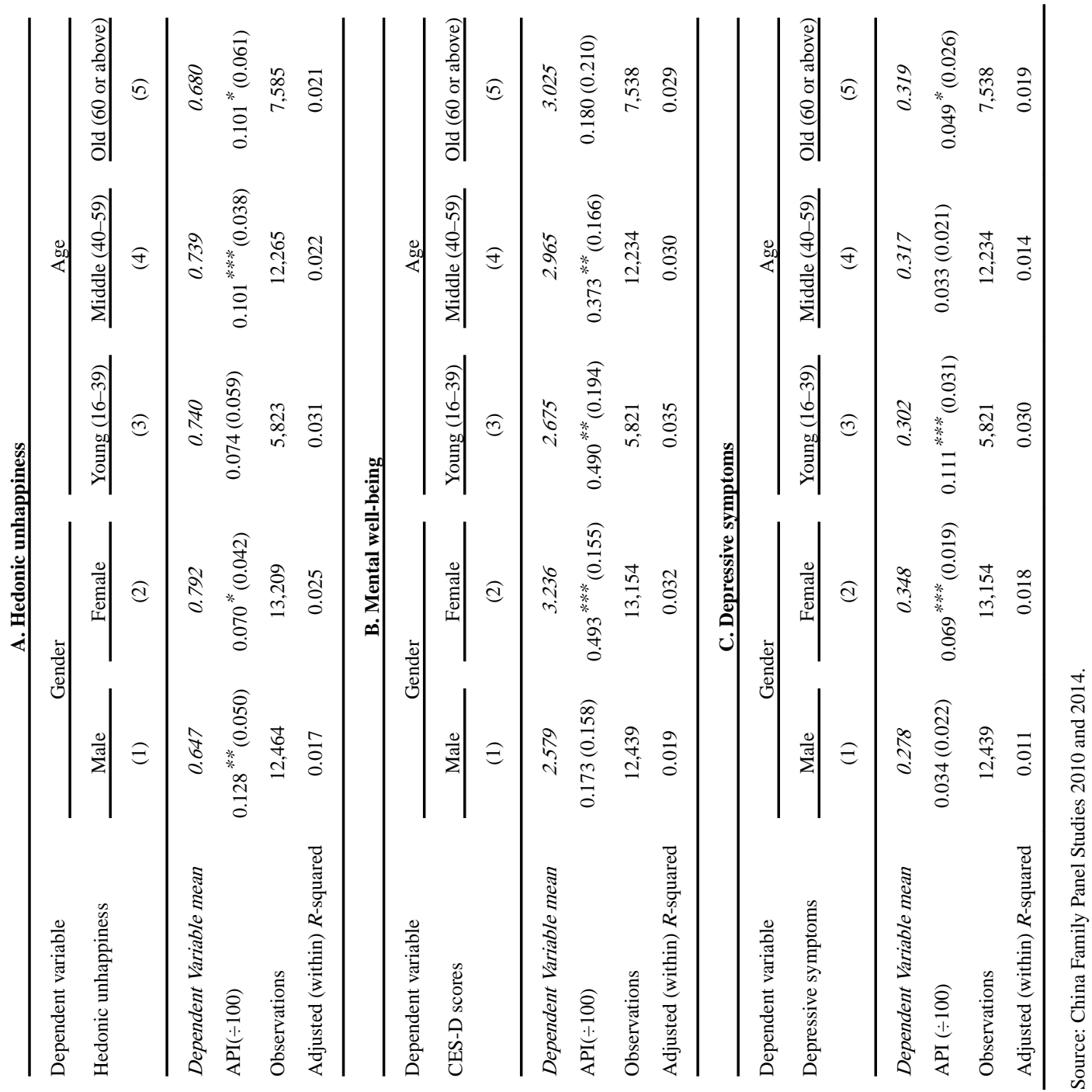




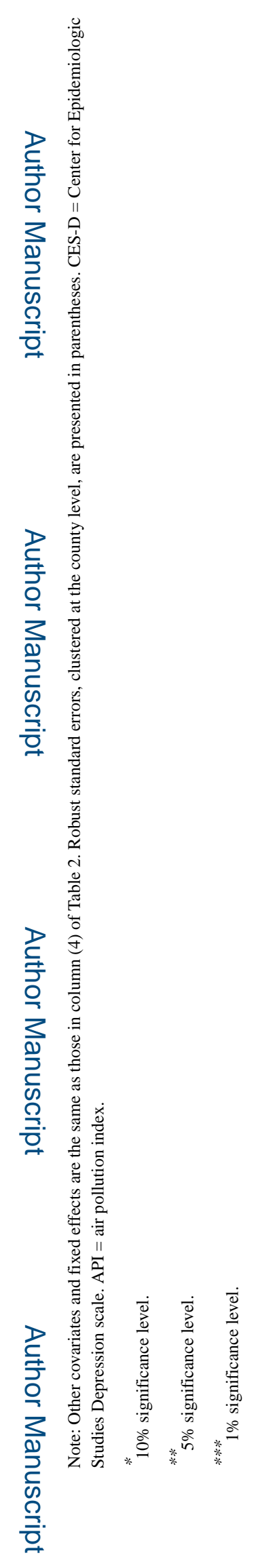

J Environ Econ Manage. Author manuscript; available in PMC 2018 September 01. 

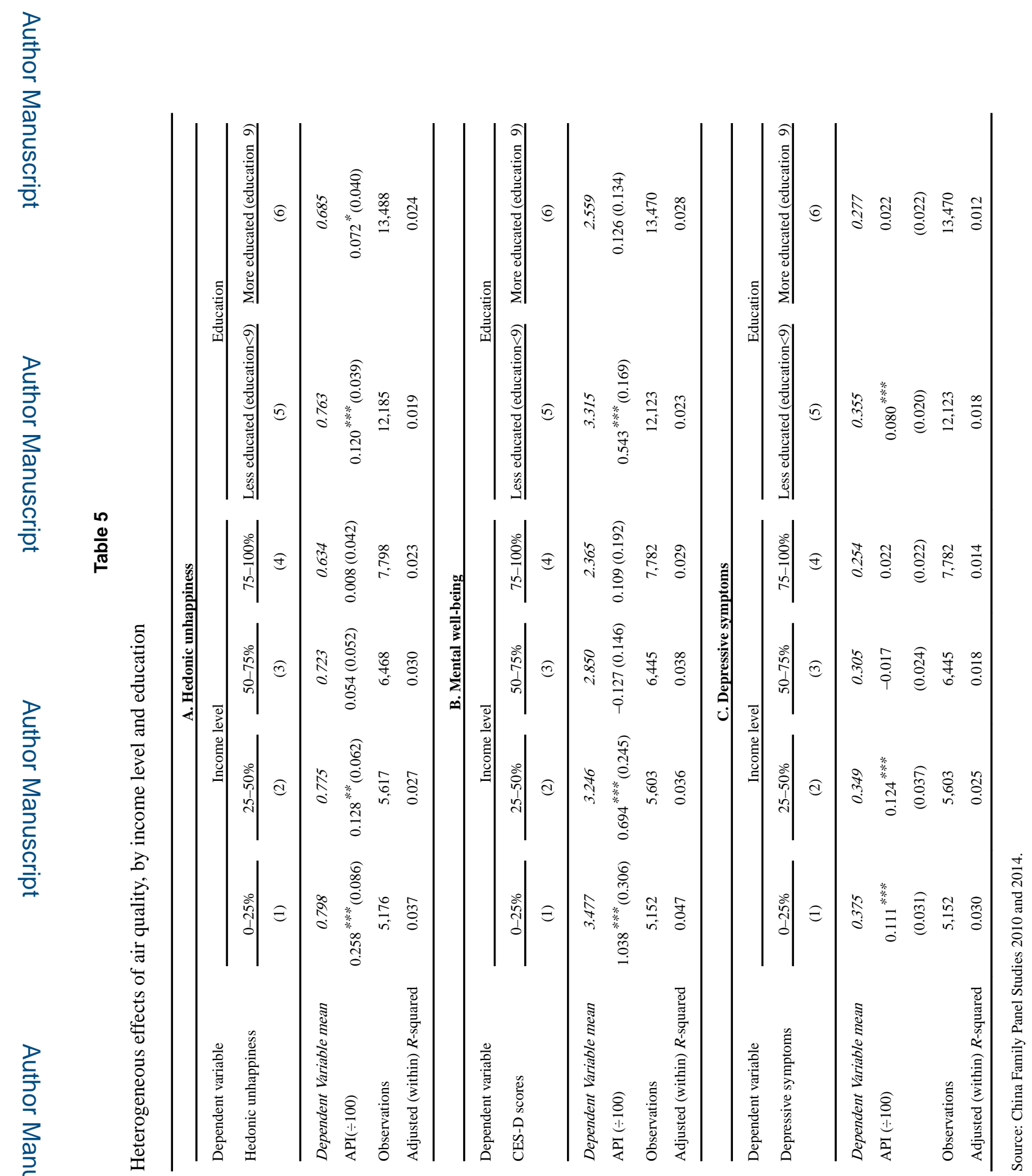

J Environ Econ Manage. Author manuscript; available in PMC 2018 September 01. 


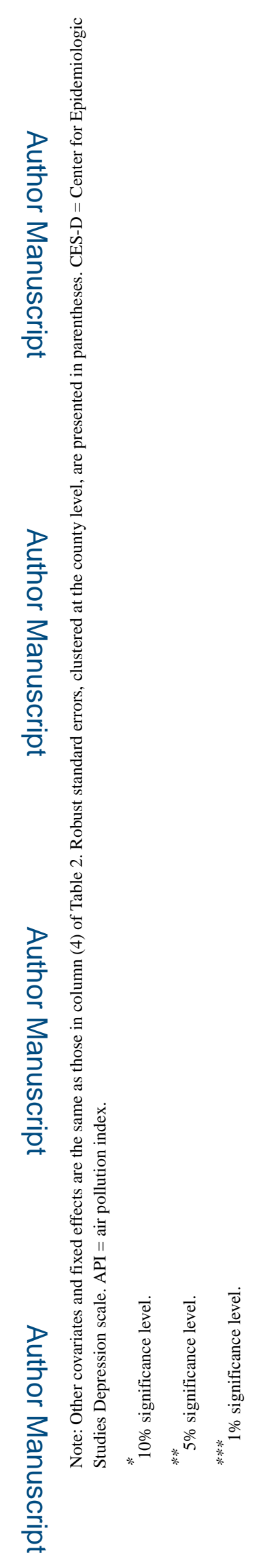

J Environ Econ Manage. Author manuscript; available in PMC 2018 September 01. 


\section{로을}

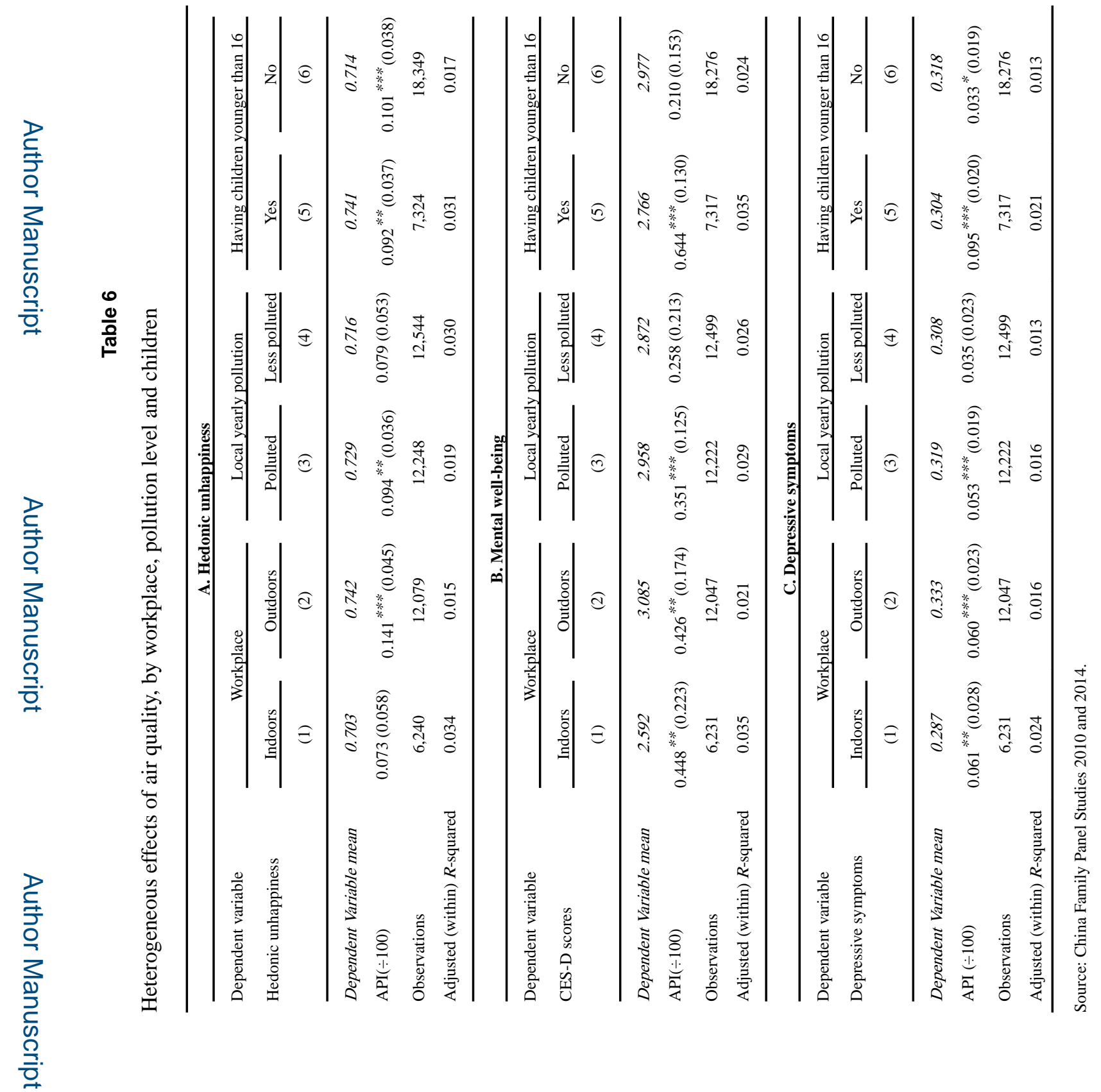




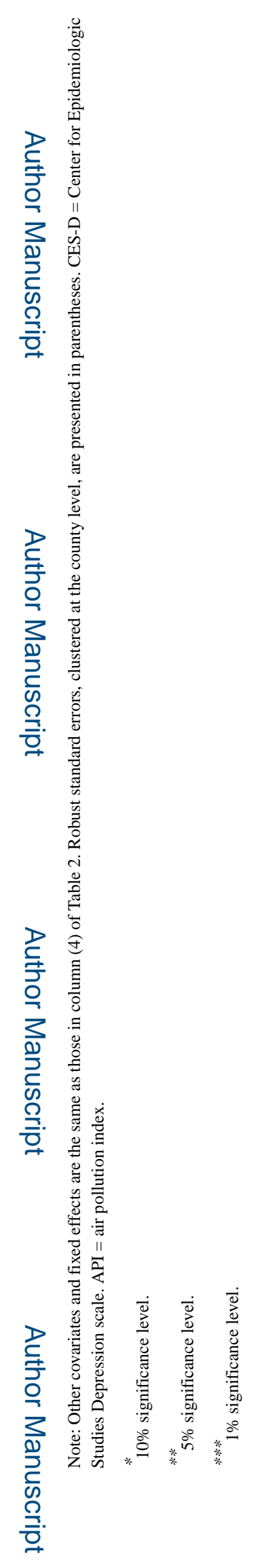

J Environ Econ Manage. Author manuscript; available in PMC 2018 September 01. 